NBER WORKING PAPER SERIES

\title{
ON THE OPTIMAL TIMING OF BENEFITS WITH HETEROGENEOUS WORKERS AND HUMAN CAPITAL DEPRECIATION
}

\author{
Robert Shimer \\ Iván Werning \\ Working Paper 12230 \\ http://www.nber.org/papers/w12230
NATIONAL BUREAU OF ECONOMIC RESEARCH
1050 Massachusetts Avenue
Cambridge, MA 02138
May 2006

Shimer's research is supported by a grant from the National Science Foundation. Werning is grateful for the hospitality of Chicago and Harvard University during the time the first draft of this paper was written. The views expressed herein are those of the author(s) and do not necessarily reflect the views of the National Bureau of Economic Research.

C2006 by Robert Shimer and Iván Werning. All rights reserved. Short sections of text, not to exceed two paragraphs, may be quoted without explicit permission provided that full credit, including $\odot$ notice, is given to the source. 
On the Optimal Timing of Benefits with Heterogeneous Workers and Human Capital Depreciation Robert Shimer and Iván Werning

NBER Working Paper No. 12230

May 2006

JEL No. J6

\begin{abstract}
This paper studies the optimal timing of unemployment insurance subsidies in a McCall search model. Risk-averse workers sequentially sample random job opportunities. Our model distinguishes unemployment subsidies from consumption during unemployment by allowing workers to save and borrow freely. When the insurance agency faces a group of homogeneous workers solving stationary search problems, the optimal subsidies are independent of unemployment duration. In contrast, when workers are heterogeneous or when human capital depreciates during the spell, the optimal subsidy is no longer constant. We explore the main determinants of the shape of the optimal subsidy schedule, isolating forces for subsidies to optimally rise or fall with duration.

Robert Shimer

Department of Economics

University of Chicago

1126 East 59th Street

Chicago, IL 60637

and NBER

shimer@uchicago.edu

Iván Werning

MIT Department of Economics

50 Memorial Drive, E51-251a

Cambridge, MA 02142-1347

and NBER

iwerning@mit.edu
\end{abstract}




\section{Introduction}

The goal of this paper is to develop a test for the optimal level of unemployment insurance using a minimal amount of economic theory and a minimal amount of data. We approach this by studying a risk-averse worker in a sequential job search setting (McCall, 1970). Our main theoretical insight is that the worker's after-tax reservation wage - the difference between her reservation wage and the tax needed to fund the unemployment insurance system - encodes all of the relevant information about her welfare. This is true regardless of whether workers are able to borrow and lend to smooth their consumption or whether they must must live hand-to-mouth.

The intuition is clear: the after-tax reservation wage tells us the take-home pay required to make a worker indifferent between working and remaining unemployed. Since take-home pay translates directly into consumption, it is a valid measure of the worker's utility. Given the simplicity of the argument, it should not be surprising that this insight turns out to be robust to several variations of our basic model.

To prove this result, we develop a formal dynamic model of job search with risk-aversion. Workers draw wages from a known distribution and accepted jobs last for a fixed amount of time. In order to abstract from wealth effects, we assume workers have constant absolute risk aversion (CARA) preferences. ${ }^{1}$ We first consider how workers behave when confronted by an arbitrary level of unemployment benefits and reemployment taxes and show how the answer depends on whether workers are able to borrow and lend. In both cases we find that a worker's utility while unemployed is a monotone function of her after-tax reservation wage. If she has no access to capital markets, her unemployment utility, measured in consumption equivalent units, is equal to her after-tax reservation wage. If she can borrow and lend, it is equal to her after-tax reservation wage plus the annuity value of her assets. This implies that optimal unemployment insurance - the policy of an agency which chooses unemployment benefits and reemployment taxes to maximize an unemployed worker's utility subject to the expected discounted cost of the unemployment insurance equally zero - simply seeks to maximize workers' after tax reservation wage.

This insight leads to a novel test for the optimality of unemployment insurance: raising benefits is desirable whenever it raises the after-tax reservation wage. This criteria can be

\footnotetext{
${ }^{1}$ In Shimer and Werning (2005), we show that the behavior and insurance needs of a worker with constant relative risk aversion (CRRA) preferences is similar to that of a worker with the same absolute risk aversion and CARA preferences. Thus we believe that the results we report here are quantitatively reasonable for more general preferences.
} 
decomposed into two effects. On the one hand, higher benefits reduce the cost of remaining unemployed and therefore raise the pre-tax reservation wage. Thus, if the pre-tax reservation wage is very responsive to unemployment benefits, raising unemployment benefits has a strong positive effect on workers' welfare. However, the increase in benefits must be funded by an increase in the employment tax. The higher is the unemployment rate or the more responsive it is to unemployment benefits, the greater is the needed increase in the tax. Our optimality condition nets out both effects.

While a large literature studies the responsiveness of unemployment or unemployment duration to unemployment benefits (e.g., Meyer, 1990), there is less research on the responsiveness of reservation wages to benefits. Two notable exceptions are Fishe (1982) and Feldstein and Poterba (1984). Fishe (1982) uses information on actual wages to infer reservation wages, while Feldstein and Poterba (1984) uses direct survey evidence on reservation wages. Both papers find that a $\$ 1$ increase in benefits may raise pre-tax reservation wages by as much as $\$ 0.44$. Feldstein and Poterba (1984) interpret this as evidence of the moral hazard cost of raising unemployment benefits, but our approach turns this logic around, since our theory tells us that the reservation wage measures the welfare of unemployed workers.

If the numbers in Fishe (1982) and Feldstein and Poterba (1984) are correct, we show that a fully-funded $\$ 1$ increase in weekly benefits, at a cost of approximately $\$ 400$ million per year in the U.S. economy, is equivalent to somehow giving every employed and unemployed worker an additional $\$ 0.37$ of consumption per week, i.e. to creating $\$ 2.6$ billion per year in additional consumption. Of course, Fishe's (1982) and Feldstein and Poterba's (1984) estimates are valid for small policy changes; according to the model, sufficiently high unemployment benefits would eventually eliminate all economic activity. Moreover, more recent estimates of the responsiveness of reservation wages to benefits are smaller and imply that current benefit levels are too high. In our view, the uncertainty around this critical variable calls for more precise estimates of it.

Within the public finance literature, the standard approach to measuring optimal unemployment insurance is based on the Baily (1978) test:

"The optimal unemployment insurance benefit level is set when the proportional drop in consumption resulting from unemployment, times the degree of relative risk aversion of workers (evaluated at the level of consumption when unemployed) is equal to the elasticity of the duration of unemployment with respect to balanced budget increases in UI [unemployment insurance] benefits and taxes." (p. 390)

While this approach is close in spirit to the one we adopt here, we see several advantages 
to our test. First, our test is entirely behavioral, while the Baily test requires independent estimates of risk-aversion. Indeed, Chetty (2005) argues within a Baily framework that the relevant risk-aversion parameter depends on the context and may be higher for unemployment risk. In light of such concerns, the fact that our test does not requires selecting this, or any other, parameter is particularly convenient.

Second, Chetty (2005) shows that in a dynamic environment, the Baily test requires a long panel data set with information on total consumption. Unfortunately, no such data set exists, so the best known implementation of the Baily test, Gruber (1997), uses panel data on food expenditure. There are two main limitations to using food expenditure as a proxy for total consumption: recent work by Aguiar and Hurst (2005) shows that the link between food expenditure and food consumption is tenuous because of varying amounts of time spent in household production; and food consumption is likely to react significantly less than total consumption to income or wealth shocks. ${ }^{2}$

Third, our exact test is robust to a number of extensions. We allow for the possibility that a worker's costly search effort affects the arrival rate of offers, that jobs may differ both in their wage and in their average tenure length, and that workers are heterogeneous but there is a single unemployment benefit system. None of these extensions affects our basic conclusion that the reservation wage is a sufficient statistic for the unemployed and therefore substantially alters our behavioral test for optimal unemployment insurance. In contrast, although Chetty (2005) shows that extensions of the consumption-based Baily test are possible, in our view they may be difficult to implement because they require an empirically challenging comparison of the average marginal utility of consumption during employment with that during unemployment over the worker's entire lifetime - a moment of consumption data not analyzed by Gruber (1997), for example. Nevertheless, our model can also deliver easily implementable consumption-based tests, but we point out that their derivation uses the full structure of the model, is less robust than the new test we propose here, and requires unexplored consumption measures from panel data.

As mentioned above, one challenge to implementing our behavioral test is that empirical evidence on reservation wages is scarce. Our hope is that this paper, by underscoring its usefulness as a welfare statistic, may lead to greater interest in reservation wage evidence, much as Baily's (1978) theoretical contribution led to empirical research on how much con-

\footnotetext{
${ }^{2}$ Indeed, Chetty (2005) extends the consumption test so that it applies to food consumption. Unfortunately, the test then requires setting a parameter for the curvature of the utility function with respect to food, instead of risk aversion.
} 
sumption declines when workers lose their job (Gruber, 1997). Ultimately, the two tests are complementary. Both assess the optimality of unemployment insurance, but exploit very different data sources.

Macroeconomists have generally taken a different approach to optimal unemployment insurance, calibrating a stochastic general equilibrium model and then performing policy experiments within the model (Hansen and Imrohoroglu, 1992; Acemoglu and Shimer, 2000; Alvarez and Veracierto, 2001). An advantage to this approach is that it can address issues we neglect, such as the impact of unemployment insurance policy on capital accumulation. But in order to do that, these papers rely heavily on the entire structure of the model and its calibration, which sometimes obscures the economic mechanisms at work and their empirical validity. This approach also makes evaluating the robustness of the results expensive. In contrast, by focusing on the worker's partial equilibrium problem - a component in richer general equilibrium models - we are able to highlight, in a tractable way, the main tradeoffs that seem important for understanding optimal unemployment insurance and to point out how the relevant forces can be measured.

A third strand of the literature focuses on the timing of benefits, and in particular, on whether unemployment benefits should fall during an unemployment spell (Shavell and Weiss, 1979; Hopenhayn and Nicolini, 1997). This paper emphasizes the optimal level of benefits but assumes that benefits and taxes are constant over time. In Shimer and Werning (2005) we argue that, provided workers are given enough liquidity to easily borrow against future earnings, ${ }^{3}$ constant benefits and taxes are optimal, or nearly so. Besides this difference in emphasis, there are two modeling differences. The first is that here we work in continuous time rather than in discrete time, a superficial change that simplifies the algebra. More importantly, here we allow for separations, so that workers experience multiple unemployment spells. This generalization is important for any quantitative exercise focusing on the level of benefits.

The remainder of the paper proceeds as follows: The next section presents our model of sequential search. Section 3 analyzes how workers behave when confronted with constant unemployment benefits and constant taxes. We consider two financial regimes. In the first, workers have unlimited access to borrowing and lending at a constant interest rate, subject only to a no Ponzi-game condition. In the second, workers must live hand-to-mouth, consuming their income in each period. Section 4 describes the problem of an insurance agency choosing the level of unemployment insurance subject to a budget constraint. Section 5

\footnotetext{
${ }^{3}$ Such liquidity might be provided by unemployment insurance savings accounts (Feldstein, 2005).
} 
describes our new test for optimal unemployment insurance and discusses the available empirical evidence that bears on the relevant parameters of that test. Section 6 considers a number of generalizations to our model and shows that our test is unaffected by those changes. Section 7 derives a version of the Baily (1978) test for our model, showing that the exact test depends on all the details of the model and hence is less robust than our behavioral test. We conclude in Section 8.

\section{Unemployment and Sequential Search}

There is a single risk-averse worker who maximizes the expected present value of utility from consumption,

$$
\mathbb{E} \int_{0}^{\infty} e^{-\rho t} u(c(t)) d t
$$

where $\rho>0$ represents the subjective discount rate in continuous time. We assume throughout the body of the paper that the utility function exhibits CARA, $u(c)=-e^{-\gamma c}$ with coefficient of absolute risk aversion $\gamma>0$.

At any moment in time a worker can be employed, at some wage $w$ with $t$ periods remaining in the job, or unemployed. An employed worker produces a flow of $w$ units of the single consumption good and pays an employment tax $\tau$. When the job ends, she becomes unemployed. An unemployed worker receives a benefit $b$ and waits for the arrival of job opportunities. The worker receives an independent wage draw from a cumulative distribution function $F$ with Poisson arrival rate $\lambda .{ }^{4}$ When a worker gets a wage offer, she observes the wage and decides whether to accept or reject it. If she accepts, employment commences immediately and the job lasts for exactly $T \leq \infty$ periods. ${ }^{5}$ If she rejects, she produces nothing and remains unemployed. The worker cannot recall past wage offers. With CARA preferences recall is not optimal, so this last assumption is not binding.

There is an unemployment insurance agency whose objective is to maximize an unemployed worker's utility by choosing a constant unemployment benefit $b$ and constant employment $\operatorname{tax} \tau,{ }^{6}$ subject to the constraint that the expected cost of the unemployment insurance

\footnotetext{
${ }^{4}$ Section 6.4 shows that our results are robust if a worker's search effort affects the arrival rate of job offers.

${ }^{5}$ Section 6.2 shows that our main results are robust if the worker draws both a wage and a job duration. Section 6.3 shows they are robust if the duration of a job is uncertain.

${ }^{6}$ In Shimer and Werning (2005) we show that this simple unemployment insurance system is optimal with no job separations when the worker can borrow and lend at interest rate $r$. With job separations, as we allow here, this simple policy may not be fully optimal, but it remains an important benchmark.
} 
system is zero when discounted at the interest rate $r=\rho .^{7}$ Let $B \equiv b+\tau$ denote the net subsidy to unemployment, the sum of the benefit a worker receives while unemployed and the employment tax she avoids paying. We show below that a worker's behavior depends only on the net unemployment subsidy.

We consider two financial environments. In the first, the worker has access to financial markets, namely a riskless borrowing and savings technology, facing only the budget constraint

$$
\dot{a}(t)=r a(t)+y(t)-c(t)
$$

and the usual no Ponzi-game condition. ${ }^{8}$ Here $a(t)$ is assets, $c(t)$ is consumption, and $y(t)$ represents current income, equal to the current after-tax wage $w(t)-\tau$ if the worker is employed, or benefits $b$, otherwise. The rate of return $r$ is the same for the worker and the unemployment insurance agency and equal to the discount rate $\rho$ for simplicity. In the second environment, the worker lives hand-to-mouth. She has no access to a savings technology, $a(t)=0$ for all $t$, and so must consume her income in each period, $c(t)=y(t)$.

We study these two extremes because they span the spectrum of financial environments and because both cases are analytically tractable. The intermediate cases cannot be in solved in closed form but could be studied numerically to see whether our two cases provide a good benchmark; doing so goes beyond the scope of this paper.

Finally, define

$$
\alpha_{t} \equiv \frac{1-e^{-r t}}{r}=\int_{0}^{t} e^{-r s} d s
$$

This is the present value of receiving an additional unit of income for the next $t$ periods. The present value of income from a new job with wage $w$ is $\alpha_{T} w$. Note that if $r=0, \alpha_{t}=t$.

\section{Worker Behavior}

We start by characterizing how a worker behaves when confronted with any constant benefit system $(b, \tau)$. We first consider a worker with no liquidity problems, that is, a worker with access to borrowing and lending at rate $r$. We then turn to the opposite end of the spectrum and consider a hand-to-mouth worker who must consume her current income.

\footnotetext{
${ }^{7}$ Section 6.1 shows that our main results are robust if the discount rate and interest rate are not equal.

8 The no-Ponzi condition states that debt must grow slower than the interest rate, $\lim _{t \rightarrow \infty} e^{-r t} a(t) \geq 0$, with probability one. Together with the budget constraints $\dot{a}(t)=r a(t)+y(t)-c(t)$, this is equivalent to imposing a single present-value constraint, with probability one.
} 


\subsection{Workers with Liquidity}

A worker who can borrow and lend at the interest rate $r=\rho$ keeps her consumption constant during an employment spell since she faces no uncertainty. She saves, however, gradually accumulating assets while on the job. In contrast, consumption steadily declines during unemployment, because remaining unemployed represents a negative permanent income shock. This is accompanied by dissavings, as assets are run down during unemployment spells. Consumption jumps up when an unemployed worker becomes employed, because finding a job is a discrete positive shock. When unemployed, the worker uses a constant reservation wage policy, accepting jobs above some threshold $\bar{w}$. Finally, the after-tax reservation wage is a sufficient statistic for the welfare of the unemployed.

We now state these results formally:

Proposition 1 Assume a worker has access to financial markets. For a given policy $(b, \tau)$, the lifetime utility of an unemployed worker with assets a is

$$
V_{u}(a)=\frac{1}{r} u(r a+\bar{w}-\tau) .
$$

The consumption of an unemployed worker with assets a and of an employed worker with assets $a, t$ periods remaining on the job, and a wage $w$ are respectively

$$
\begin{aligned}
c_{u}(a) & =r a+\bar{w}-\tau, \\
c(a, t, w) & =r\left(a+\alpha_{t}(w-\bar{w})\right)+\bar{w}-\tau .
\end{aligned}
$$

The reservation wage $\bar{w}$ is constant and solves

$$
\gamma(\bar{w}-B)=\frac{\lambda}{r} \int_{\bar{w}}^{\infty}\left(1+u\left(r \alpha_{T}(w-\bar{w})\right)\right) d F(w)
$$

For the purposes of this paper, the most important part of this proposition is equation (1). To get some intuition for this result, suppose a worker could accept a job at wage $w$ that lasts forever, so her after-tax income would be $w-\tau$ in all future periods. With the discount rate equal to the interest rate, a worker with a concave utility function $u$ would keep her consumption constant and so would consume this income plus the annuity value on her assets, $r a$. That is, she would consume $c(a, \infty, w)=r a+w-\tau$, her assets would be constant, $\dot{a}=0$, and her lifetime utility would be $\frac{1}{r} u(r a+w-\tau)$. Now define the reservation wage $\bar{w}$ so that an unemployed worker without a job offer is indifferent between remaining unemployed and 
working forever at $\bar{w}, V_{u}(a) \equiv \frac{1}{r} u(r a+\bar{w}-\tau)$, giving equation (1).

This logic is so simple that it might seem to extend beyond our specific model. The catch lies in the notion of a reservation wage. In general, a worker may be willing to accept a wage for a finite amount of time but unwilling to take the wage forever. For example, a worker may take a low wage for a while, accumulate assets, and eventually quit to search for a higher wage. Acemoglu and Shimer (1999) explore this possibility in an environment with decreasing absolute risk aversion. We prove in Appendix A that this cannot happen with CARA preferences since a worker's attitude towards risk and hence her reservation wage is independent of assets.

\subsection{Hand-to-Mouth Workers}

We now consider worker behavior under an extreme alternative, financial autarky, so a worker must consume her income in each period: $c_{u}^{\text {aut }}=b$ and $c_{e}^{\text {aut }}(w)=w-\tau$. Under financial autarky, a worker's consumption will typically jump up when she finds a job and down when she leaves her job. Although this is qualitatively different than when the worker has access to financial markets, one critical property is unchanged, the worker's lifetime utility depends only on her after-tax reservation wage:

Proposition 2 Assume a worker must consume her income. For a given policy $(b, \tau)$, the lifetime utility of unemployment is

$$
V_{u}^{a u t}=\frac{1}{\rho} u\left(\bar{w}^{a u t}-\tau\right)
$$

where $\bar{w}^{\text {aut }}$ is the reservation wage, the solution to

$$
u\left(\bar{w}^{a u t}-\tau\right)=u(b)+\alpha_{T} \lambda \int_{\bar{w}^{a u t}}^{\infty}\left(u(w-\tau)-u\left(\bar{w}^{a u t}-\tau\right)\right) d F(w)
$$

This result is independent of the form of the period utility function $u$.

To prove this result, we use a pair of recursive equations. Let $V_{u}^{\text {aut }}$ denote the expected utility of an unemployed worker living under autarky and let $V_{e}^{\text {aut }}(w, T)$ denote the corre- 
sponding value for a newly-employed worker at a wage $w$. These solve

$$
\begin{gathered}
\rho V_{u}^{\text {aut }}=u(b)+\lambda \int_{0}^{\infty} \max \left\{V_{e}^{\text {aut }}(w, T)-V_{u}^{\text {aut }}, 0\right\} d F(w) \\
V_{e}^{\text {aut }}(w, T)=\int_{0}^{T} e^{-\rho t} u(w-\tau) d t+e^{-\rho T} V_{u}^{\text {aut }}
\end{gathered}
$$

The flow value of an unemployed worker comes from her current utility $u(b)$. In addition, at rate $\lambda$ she gets a wage draw $w$ which she may accept, giving capital gain $V_{e}^{\text {aut }}(w, T)-V_{u}^{\text {aut }}$, or reject. An employed worker in a new job earns $u(w-\tau)$ for the next $T$ periods and then has continuation value $V_{u}^{\text {aut }}$.

The Bellman equation for a newly-employed worker implies

$$
V_{e}^{\text {aut }}(w, T)-V_{u}^{\text {aut }}=\alpha_{T}\left(u(w-\tau)-\rho V_{u}^{\text {aut }}\right),
$$

since $\rho=r$, so the reservation wage solves $u\left(\bar{w}^{\text {aut }}-\tau\right)=\rho V_{u}^{\text {aut }}$. Equivalently, the lifetime utility of an unemployed worker is given by equation (5). Substituting this into the Bellman equation for an unemployed worker gives equation (6) for the reservation wage.

It is worth noting that, since the reservation wage summarizes a worker's utility both under perfect liquidity and financial autarky, the difference in the reservation wage summarizes the value of access to financial markets. More precisely,

Proposition 3 A hand-to-mouth worker has a lower reservation wage then a worker with access to capital markets. Moreover, the difference in their reservation wages is the utility gain from access to capital markets, measured in units of per-period consumption.

The proof is in Appendix B.

\section{Optimal Unemployment Insurance}

We now turn to the problem of an unemployment insurance agency which chooses the unemployment benefit $b$ and the employment tax $\tau$ to maximize an unemployed worker's utility. The agency recognizes that the worker chooses her reservation wage optimally, as described in the previous section. Thus benefits and taxes affect the expected discounted net cost of the unemployment insurance agency; we require that this is equal to zero, which turns out 
to be equivalent to

$$
\frac{b}{\lambda(1-F(\bar{w}))}=\alpha_{T} \tau
$$

The left hand side is the expected cost of unemployment benefits during one unemployment spell, the value of benefits divided by the hazard rate of finding an acceptable job. The right hand side is the product of the reemployment tax and the factor $\alpha_{T}$, the present value of a unit of income for the duration of a job. Putting this together, the optimal unemployment insurance problem is to choose benefits $b$, taxes $\tau$, and a reservation wage $\bar{w}$ to maximize the unemployed worker's utility given by equation (1) or equation (5), or equivalently $\bar{w}-\tau$, subject to the reservation wage equation (4) or equation (6) and the budget balance equation (7).

The balanced budget constraint seems natural in a large economy where wage draws are independent across workers. If all workers are initially unemployed, it should be clear why we call this optimal unemployment insurance. If some workers start off employed, however, their interests are not perfectly aligned with those of unemployed workers since initially-employed workers pay taxes now and only receive benefits later. That is, if we start with some workers employed and some unemployed, optimal benefit policy has elements of both insurance and redistribution. To focus on insurance, we implicitly assume that the unemployment insurance agency does not start taxing workers until they begin their first unemployment spell. Equivalently, we assume the agency has access to lump-sum transfers conditional on a worker's initial employment status. Although we do not view this assumption as realistic, it realigns the interests of employed and unemployed workers and allows us to focus on insurance rather than redistribution.

\section{A Behavioral Test}

Optimal unemployment benefits maximize a worker's after-tax reservation wage $\bar{w}-\tau$ when the tax is set to balance the budget in equation (7). To see whether this condition holds, all we need to know is how a balanced-budget increase in taxes and benefits affects a worker's after-tax reservation wage. It is not necessary to make any assumptions about risk-aversion, discount rates, the speed of finding a job, the duration of a job, the distribution of wage offers,

or about whether workers have liquidity or must consume hand-to-mouth since workers' utility is a monotone function of the after-tax reservation wage $\bar{w}-\tau$.

While this result is theoretically appealing, it may be difficult to implement because it 
may be hard to discern how much taxes must rise to balance an increase in benefits. In principle this question might be left to a budgetary authority like the Congressional Budget Office, but such an organization would still need to understand how much the increase in benefits raises unemployment duration. Instead, we show that if we can observe how unemployment benefits affect the pre-tax reservation wage, then we can use information on the elasticity of unemployment duration with respect to benefits to characterize how taxes must change and hence to characterize optimal policy.

\subsection{Theory}

Equation (4) or equation (6) implies that the reservation wage depends on unemployment benefits and taxes, $\bar{w}(b, \tau)$. It follows that the resource constraint (7) defines taxes as a function of benefits,

$$
D(b, \tau(b)) b=\alpha_{T} \tau(b)
$$

where $D(b, \tau) \equiv 1 / \lambda(1-F(\bar{w}(b, \tau)))$ is the expected duration of an unemployment spell. Differentiate this with respect to $b$ to get

$$
\tau^{\prime}(b)=\frac{b D_{b}(b, \tau(b))+D(b, \tau(b))}{\alpha_{T}-b D_{\tau}(b, \tau(b))}
$$

where subscripts denote partial derivatives. With CARA utility and either perfect liquidity or hand-to-mouth consumption, the reservation wage and hence unemployment duration depends only on the sum of benefits and taxes (see equation 4 and equation 6 , respectively), so $D_{b}=D_{\tau}$. Then letting $\varepsilon_{D, b} \equiv b D_{b}(b, \tau) / D(b, \tau)$ be the the elasticity of unemployment duration with respect to unemployment benefits, we can write the previous equation as

$$
\tau^{\prime}(b)=\frac{D(b, \tau(b))\left(1+\varepsilon_{D, b}\right)}{\alpha_{T}-D(b, \tau(b)) \varepsilon_{D, b}} .
$$

Next, since unemployment benefits should maximize $\bar{w}(b, \tau(b))-\tau(b)$, a necessary condition for optimal benefits is

$$
\bar{w}_{b}(b, \tau(b))+\bar{w}_{\tau}(b, \tau(b)) \tau^{\prime}(b)=\tau^{\prime}(b),
$$

where as usual subscripts denote partial derivatives. Again, $\bar{w}_{b}=\bar{w}_{\tau}$ under CARA utility, and so combining this equation with equation (9) gives our test for optimal benefits: 
Proposition 4 If unemployment benefits are optimal,

$$
\bar{w}_{b}=\frac{D}{\alpha_{T}+D}\left(1+\varepsilon_{D, b}\right) .
$$

If the left-hand-side of equation (10) is larger than the right-hand-side, an increase in benefits has a big effect on the reservation wage and hence on workers' utility relative to the tax cost, and so a small increase is welfare-improving.

Roughly speaking, the coefficient $\frac{D}{\alpha_{T}+D}$ represents the fraction of time that a worker spends unemployed. More precisely, suppose we pay a worker $1 / r$ each period she is unemployed. If the worker starts off unemployed, the expected cost is $\frac{D}{\alpha_{T}+D}$. In the limit as $r \rightarrow 0, \alpha_{T} \rightarrow T$, so this is just the fraction of time the worker spends unemployed, i.e. the unemployment rate $u \equiv \frac{D}{T+D}$. At an optimum, a unit increase in unemployment benefits should raise the reservation wage by the unemployment rate times 1 plus the elasticity of unemployment duration with respect to unemployment benefits. If there is discounting, $\frac{D}{\alpha_{T}+D}$ is slightly larger than the unemployment rate, but in practice the difference is quantitatively small.

\subsection{Measurement}

To implement the test proposed in Proposition 4, think of the time unit as a week and set the interest rate at $r=0.001$, equivalent to an annual interest rate of 5.1 percent. We set expected unemployment duration at $D=10$ weeks and the duration of a job at $T=165$ weeks, consistent with a 5.7 percent unemployment rate, the average value in the U.S. since 1948. According to Meyer (1990, p. 779), the elasticity of the hazard rate of finding a job with respect to benefits is -0.88 ; since the hazard rate is the inverse of expected unemployment duration, this implies $\varepsilon_{D, b}=0.88$. This estimate is somewhat larger than 0.5, which Krueger and Meyer (2002, p. 2351) call "not an unreasonable rough summary" of the literature, and so provides a conservative bound for the cost of raising unemployment benefits. ${ }^{9}$ With $\varepsilon_{D, b}=0.88$, the right hand side of equation (10) evaluates

\footnotetext{
${ }^{9}$ The elasticity $\varepsilon_{D, b}$ is partial, holding taxes constant, not the elasticity of duration with respect to an increase in benefits and a balanced-budget increase in taxes. Most of the theoretical literature has focused on the latter concept, but our reading of the empirical literature suggests that it measures the partial elasticity and so we define the elasticity that way here. In any case, interpreting Meyer's estimates as a partial elasticity is again the conservative choice. If they in fact give the impact of a balanced-budget change in unemployment benefits and employment taxes, $\hat{\varepsilon}_{D, b}=0.88$, one can show that the elasticity of duration with respect to benefits alone is slightly smaller, $\varepsilon_{D, b}=\hat{\varepsilon}_{D, b} \alpha_{T} /\left(\left(1+\hat{\varepsilon}_{D, b}\right) D+\alpha_{T}\right)=0.78$.
} 
to 0.116. Reasonable parameter changes do not much affect this number. For example, if unemployment duration is twice as long, $D=20$, but job duration is also twice as long, $T=330$, so the unemployment rate is unchanged, the right hand side increases slightly to 0.125 .

There are several studies that estimate the responsiveness of the reservation wage to unemployment benefits. ${ }^{10}$ In our view, none of these calculations is definitive. Instead, the different answers they provide point to the need for more precise estimates of the responsiveness of reservation wages to benefits. Fishe (1982) uses the Continuous Wage and Benefit History files for Florida, a 5 percent sample of state residents from 1971 to 1974. He infers the reservation wage from information on actual wages. His Table 2 shows that a $\$ 1$ increase in potential weekly benefits raises the (unobserved) reservation wage by $\$ 0.44$.

If this estimate is correct, there is a substantial gain from raising unemployment benefits. A $\$ 1$ balanced-budget increase in unemployment benefits raises the after-tax reservation wage by

$$
\bar{w}_{b}\left(1+\tau^{\prime}(b)\right)-\tau^{\prime}(b)=\frac{\bar{w}_{b}\left(\alpha_{T}+D\right)-D\left(1+\varepsilon_{D, b}\right)}{\alpha_{T}-D \varepsilon_{D, b}},
$$

or $\$ 0.37$ using Fishe's (1982) number for $\bar{w}_{b}$. Measuring utility in units of consumption, this raises the welfare of all unemployed workers by the same amount as giving them 37 cents of additional consumption at all dates in the future, but the increase in unemployment benefits is revenue neutral. Put differently, there are about 135 million workers in the U.S. economy, with about 7.7 million unemployed at any point in time. Raising unemployment benefits by $\$ 1$ per week would cost approximately $\$ 400$ million per year. This is equivalent to (somehow) raising the consumption of all workers by $\$ 0.37$ per week, at a cost of $\$ 2.6$ billion per year. Of course, even if these estimates are correct, they are only correct locally. Raising benefits by $\$ 1000$ per week would probably not yield $\$ 2.6$ trillion per year in additional consumption-equivalent utility.

Another approach uses self-reported reservation wages. Feldstein and Poterba (1984) study a supplement to the May 1976 Current Population Survey (CPS) that includes such information. In their Table 4, they report that a 1 percentage point increase in the ratio of unemployment benefits $b$ to the previous wage $w_{0}$ raises the ratio of the reservation wage $\bar{w}$ to the previous wage $w_{0}$ by somewhere between 0.13 and 0.42 percentage points, so $\bar{w}_{b} \in[0.13,0.42]$. The lowest slope estimate is for job losers on layoff and the highest is for

\footnotetext{
${ }^{10}$ Early but indirect evidence that the reservation wage responds to unemployment benefits comes from Ehrenberg and Oaxaca (1976), who find that workers who receive higher unemployment benefits get higher wage jobs.
} 
other job losers; the slope estimate for job leavers is 0.29 . This study also therefore suggests substantial gains from increasing unemployment benefits. Curiously, Feldstein and Poterba (1984) interpret their estimates of the responsiveness of reservation wages to benefits as an argument for lowering unemployment benefits because of the moral hazard costs. Our model shows that, on the contrary, if the reservation wage is sufficiently responsive to benefits, then benefits must be serving their purpose, improving the welfare of unemployed workers.

On the other hand, some more recent estimates of $\bar{w}_{b}$ from other countries are smaller. For example, a recent study by Bloemen and Stancanelli (2001) uses self-reported reservation wages for unemployed workers in the Dutch socio-economic panel from 1987 to 1990. They report in their Table 4 that a 1000 Florin increase in unemployment income raises the reservation wage of household heads by 4.4 percent and of spouses by 9.0 percent, although the latter figure is not statistically different from zero. Since the mean reservation wage is 1521 Florin for household heads and 828 Florin for spouses (see their Table 1), the estimated value of $\bar{w}_{b}$ is 0.07 for both groups. Taking this small estimate at face value, it suggests that current benefit levels are too high and that reducing benefits by $\$ 1$ is equivalent to a permanent 5 cent increase in consumption. Of course, there are some problems with this calculation since it compares estimates of the elasticity of unemployment duration from the U.S. with estimates of the slope of the reservation wage function from the Netherlands, a country with relatively high unemployment benefits. Still, it clarifies the need for more precise and up-to-date estimates of $\bar{w}_{b}$.

\section{$6 \quad$ Extensions}

We think the most attractive feature of the behavioral test for optimal unemployment insurance is that, while it is theoretically well-grounded, it does not rely on much of the structure of the model. For example, we have already shown that we do not need to know whether workers have easy access to financial markets or no access at all. In this section, we discuss several modifications of and extensions to our basic framework in order to establish the robustness of our approach. Each of these modifications alters the formula for how the reservation wage reacts to benefits, but none of them substantially changes the behavioral test in Proposition 4. To simplify the presentation we discuss each new element separately and keep the mathematical formalities to a minimum. 


\subsection{Different Interest and Discount Rates}

To simplify the exposition we have assumed throughout that the interest rate is equal to the discount rate. Fortunately, our characterization of optimal unemployment insurance does not depend on the relationship between $r$ and $\rho$. While the relationship between $r$ and $\rho$ affects consumption, it is easy to show that with CARA preferences the effect is simply a level-shift in consumption:

$$
c_{u}(a)=r a+\bar{w}-\tau+\frac{\rho-r}{r \gamma},
$$

where $\gamma$ is the coefficient of absolute risk aversion Therefore the objective of the unemployment insurance agency is still to maximizing the after-tax reservation wage subject to the budget constraint in equation (7) and so the characterization in equation (10) is unchanged. ${ }^{11}$

\subsection{Heterogeneity in Job Length}

In our baseline model, we assumed that all jobs last for $T$ periods and are heterogeneous only in the wage opportunity. We now prove that our results easily extend to the case when jobs differ both in terms of their wage offer and in terms of their duration.

Suppose that workers sample jobs distinguished by their wage-duration pair $(w, T)$ from some joint distribution function $F(w, T)$. It is straightforward to prove that workers use a reservation wage rule, accepting all jobs that pay at least $\bar{w}$, independent of $T$. Intuitively, a worker employed at her reservation wage is indifferent about accepting the job and therefore indifferent about how long the job lasts. In particular, an unemployed worker with assets $a$ is indifferent about accepting a job offering her reservation wage forever, and therefore consuming $r a+\bar{w}-\tau$ forever. This pins the value of unemployment, unchanged from equation (1) in the case with liquidity and equation (5) in the case of financial autarky. In both cases, a worker's utility is still increasing in the after-tax reservation wage $\bar{w}-\tau$.

Optimal unemployment insurance maximizes the after-tax reservation wage subject the resource constraint, a slight generalization of equation (7):

$$
\frac{b}{\lambda(1-F(\bar{w}))}=\mathbb{E}\left(\alpha_{T} \mid w \geq \bar{w}\right) \tau,
$$

where $\mathbb{E}\left(\alpha_{T} \mid w \geq \bar{w}\right)$ is the expected value of $\alpha_{T}$ conditional on a wage draw exceeding the reservation wage. If $w$ and $T$ are independent, $\mathbb{E}\left(\alpha_{T} \mid w \geq \bar{w}\right)=\mathbb{E} \alpha_{T}$, the unconditional

\footnotetext{
11 This argument ignores any possible general equilibrium effects of unemployment benefits on interest rates, a channel that we think is unlikely to be quantitatively important.
} 
expected value of $\alpha_{T}$, and so our behavioral characterization of optimal unemployment insurance is virtually unchanged from equation (10):

$$
\bar{w}_{b}=\frac{D}{\mathbb{E} \alpha_{T}+D}\left(1+\varepsilon_{D, b}\right) .
$$

In general, however, the expected value of $\alpha_{T}$ depends on the reservation wage and hence on benefits and taxes. This leads to the following generalization of equation (10):

$$
\bar{w}_{b}=\frac{D}{\hat{\alpha}+D}\left(1+\varepsilon_{D, b}-\varepsilon_{\hat{\alpha}, b}\right)
$$

where $\hat{\alpha} \equiv \mathbb{E}\left(\alpha_{T} \mid w \geq \bar{w}\right)$ and $\varepsilon_{\hat{\alpha}, b}$ is the elasticity of $\hat{\alpha}$ with respect to benefits. For example, if higher wage jobs last longer, an increase in benefits raises both employment duration so $\varepsilon_{\hat{\alpha}, b}>0$.

This equation is easy to interpret if $r=0$ so $\hat{\alpha}$ measures the average duration of an

employment spell, $\mathbb{E}(T \mid w \geq \bar{w})$. Since the unemployment rate is $\frac{D}{\mathbb{E}(T \mid w \geq \bar{w})+D}$ and the employment rate is $\frac{\mathbb{E}(T \mid w \geq \bar{w})}{\mathbb{E}(T \mid w \geq \bar{w})+D}$, the difference in elasticities, $\varepsilon_{D, b}-\varepsilon_{\hat{\alpha}, b}$, is the elasticity of the unemployment-employment ratio with respect to benefits. If higher wage jobs tend to last for longer, the increase in employment duration from an increase in benefits offsets the increase in unemployment duration, reducing the relevant elasticity and raising the attractiveness of unemployment insurance. To our knowledge, the existing literature on optimal unemployment insurance has neglected this possibility.

\subsection{Job Loss Risk}

To focus on the risk of unemployment duration we abstracted from job loss risk by assuming that the duration of a job is known as soon as the job is accepted. In reality, of course, workers do face uncertainty regarding job length, and would value insurance against the risk of early separations.

If all job losses are exogenous - that is, if there is no form of moral-hazard involved - then it is optimal to fully insure against these shocks. The right instrument to address this would not be unemployment insurance, which pays some benefit per period remaining unemployed, but a lump-sum severance payment at the time of dismissal. The fact that unemployment insurance is not the obvious instrument for this risk was part of our motivation for abstracting from job loss risk in our baseline model. However, even in this case it may still be of interest to understand the determinants of unemployment insurance when such severance payments 
are ruled out. Once again, our behavioral test is virtually unaffected.

To be concrete, suppose all jobs end according to a Poisson process with arrival rate $s$. Since a worker earning her reservation wage is indifferent about when her job ends, she effectively faces no uncertainty and therefore keeps her consumption and assets constant: $c^{s}(a, \bar{w})=c_{u}(a)=r a+\bar{w}-\tau$. This pins down the value of unemployment, an increasing function of the after-tax reservation wage with both financial market structures.

The resource constraint changes slightly when job duration is uncertain, so equation (7) becomes

$$
\frac{b}{\lambda(1-F(\bar{w}))}=\frac{\tau}{r+s} \tau .
$$

Note that $1 /(r+s)$ represents the expected present value of a unit of income until a job ends, analogous to $\alpha_{T}$ in the case of finite jobs. This modification carries through the algebra until equation (10), yielding the optimality condition

$$
\bar{w}_{b}=\frac{D}{\frac{1}{r+s}+D}\left(1+\varepsilon_{D, b}\right) .
$$

Setting $r=0.001, D=10, s=1 / T=1 / 165$, and $\varepsilon_{D, b}=0.88$, the right hand side evaluates to 0.124 , slightly larger than the 0.116 obtained when all jobs last for exactly $T$ periods.

Indeed, the only difference between these numbers comes from discounting. If $r=0, \frac{D}{T+D}$ and $\frac{D}{1 / s+D}$ are both equal to the unemployment rate.

Of course, we can also examine what happens when the hazard of job loss varies across jobs. If $w$ and $s$ are independent, the expected value of $1 /(r+s)$ enters the denominator of equation (12). If they are correlated, the term in the denominator must condition on the wage exceeding $\bar{w}$ and the relevant elasticity is that of the unemployment-employment ratio with respect to benefits, exactly as in the model without job loss risk.

\subsection{Costly Search}

We have so far focused on a worker's choice of which jobs to accept as the source for the moral-hazard problem. An alternative approach models workers as making a costly search effort choice that affects the arrival rate of a homogeneous job opportunities. Reality likely combines both elements; fortunately, so can our model.

To maintain the tractability of our CARA specification with no wealth effects on job choices, we assume that the search effort is monetary so that the utility function is $u(c-v(e))$ for some disutility of effort function $v(e)$, where $e$ is effort. Effort improves the arrival of job 
opportunities $\lambda(e)$.

With this specification, workers optimally choose some constant level of effort $e^{*}$, independent of their wealth level. Effectively this reduces unemployment income by $v\left(e^{*}\right)$. While this naturally alters the reservation wage equation (4), it does not alter the value of an unemployed worker conditional on her reservation wage, which is unchanged from equation (1) and equation (5). Similarly, the budget constraint equation (7) is unchanged by introducing search effort, although one must recognize that the arrival rate of job offers and the reservation wage are both affected by policy. The bottom line is that our main result is unaffected by this modification since all that matters for deriving equation (10) is the elasticity of unemployment duration with respect to benefits, not the reason why benefits affect unemployment duration. Thus Proposition 4 is unchanged by a monetary cost of search.

\subsection{Worker Heterogeneity}

Up to this point we have considered the problem of an insurance agency confronted with a single worker. Obviously, this problem is also of immediate relevance if there are many identical workers. The analysis is also immediately applicable if there are many heterogeneous workers, and the agency can tailor the unemployment insurance design to each type of worker. We now pursue a generalization that allows worker heterogeneity but assumes that there can be only one unemployment insurance policy that applies to all worker types.

There are finitely many types of workers denoted by $n=1,2, \ldots N$ with population fractions $\pi^{n}$. We allow the distribution of wages $F^{n}(w)$, the duration of jobs $T^{n}$, and the risk aversion parameter $\gamma^{n}$ to depend on the worker type. To motivate our welfare criterion, we assume worker types are observable and that lump-sum transfers are feasible. We introduce lump-sum transfers to focus the problem on insurance rather than redistribution. If lump-sum transfers were infeasible, unemployment benefits have both an insurance and a redistributive role, much like in an economy where some workers are initially employed and some are initially unemployed. With lump-sum transfers across types and initial employment status, the objective is simply to maximize average consumption-equivalent welfare, which using equation (1) or equation (5) is

$$
\sum_{n=1}^{N} \bar{w}^{n} \pi^{n}-\tau
$$

where $\bar{w}^{n}$ represents the reservation wage used by a type $n$. 
We require that the unemployment insurance agency's budget balances when averaged across types:

$$
b \hat{D}=\tau \hat{\alpha}
$$

where

$$
\hat{D} \equiv \frac{\sum_{n=1}^{N} \frac{D^{n} \pi^{n}}{D^{n}+\alpha^{n}}}{\sum_{n=1}^{N} \frac{\pi^{n}}{D^{n}+\alpha^{n}}} \quad \text { and } \quad \hat{\alpha} \equiv \frac{\sum_{n=1}^{N} \frac{\alpha^{n} \pi^{n}}{D^{n}+\alpha^{n}}}{\sum_{n=1}^{N} \frac{\pi^{n}}{D^{n}+\alpha^{n}}}
$$

are, loosely speaking, the average duration of unemployment and employment spells, weighted to downplay workers who experience fewer unemployment spells, either because their unemployment duration $D^{n}$ or their employment duration $T^{n}$ and hence $\alpha^{n}$ is longer.

In the special case of $r=0, \alpha^{n}=T^{n}$. Since type $n$ workers spend a fraction $u^{n}=$ $D^{n} /\left(D^{n}+T^{n}\right)$ of their life unemployed, these expressions simplify further:

$$
\frac{\hat{D}}{\hat{\alpha}}=\frac{\sum_{n=1}^{N} u^{n} \pi^{n}}{\sum_{n=1}^{N}\left(1-u^{n}\right) \pi^{n}}=\frac{\hat{u}}{1-\hat{u}},
$$

where $\hat{u}$ is the population unemployment rate. Thus $\hat{D} / \hat{\alpha}$ measures the employmentunemployment ratio when $r=0$.

To summarize, optimal policy consists of a choice of benefits and taxes which maximizes the average after-tax reservation wage in equation (13) subject to the budget constraint in equation (14). This gives the following necessary condition for optimal policy, analogous to equation (11):

$$
\sum_{n=1}^{N} \bar{w}_{b}^{n} \pi^{n}=\frac{\hat{D}}{\hat{\alpha}+\hat{D}}\left(1+\varepsilon_{\hat{D}, b}-\varepsilon_{\hat{\alpha}, b}\right),
$$

where $\bar{w}_{b}^{n}$ is the derivative of the reservation wage of type $n$ workers with respect to the benefit level $b$.

The left-hand-side of this equation uses the population weights $\pi^{n}$ and thus corresponds to studies like Fishe (1982), who infers reservation wages from a representative sample of Florida's population. This is not necessarily equal to the average value of $\bar{w}_{b}^{n}$ among unemployed workers, the quantity that Feldstein and Poterba (1984) and Bloemen and Stancanelli (2001) measure using self-reported reservation wages.

When there is no discounting, the right-hand-side of equation (15) only requires data on the unemployment rate and its responsiveness to benefits:

$$
\frac{\hat{D}}{\hat{\alpha}+\hat{D}}\left(1+\varepsilon_{\hat{D}, b}-\varepsilon_{\hat{\alpha}, b}\right)=\hat{u}\left(1+\varepsilon_{\hat{u}, b}-\varepsilon_{1-\hat{u}, b}\right),
$$


where $\varepsilon_{\hat{u}, b}$ and $\varepsilon_{1-\hat{u}, b}$ are the elasticity of the unemployment rate and the employment rate with respect to benefits. With a quantitatively reasonable amount of discounting, this approximation is likely to be close.

\section{A Consumption-Response Test}

The goal of this section is to link our model with existing tests for optimal unemployment insurance which are based on the response of consumption to becoming unemployed (Baily, 1978; Gruber, 1997; Chetty, 2005). To do this, we return to the benchmark model of Section 2 and show how we can use the full structure to derive a test linking the decline in consumption during an unemployment spell to risk aversion and the elasticity of unemployment duration with respect to benefits. Our exact test depends on whether workers have liquidity. If they do, our test looks at the average drop in consumption during an unemployment spell. In the hand-to-mouth model, our test examines the difference in consumption between an unemployed worker and a worker employed at her reservation wage. It should be clear that each of the extensions analyzed in Section 6 would potentially introduce further modifications to our consumption-response tests since, in contrast to our behavioral test, these tests build on the full structure of the model including the determinants of consumption and reservation wages.

It is possible to derive other consumption-based tests that do not rely heavily on the structure of the model, including ones which are identical in the hand-to-mouth and liquidity cases (Chetty, 2005). Unfortunately, such tests tell us to compare the average lifetime marginal utility of a worker when employed and when unemployed. To implement such tests, we either need a very rich data set on the lifetime path of consumption for a large panel of individuals or we have to make some implicit assumption about the economic environment so that we can extrapolate the desired moments from a limited data set. In contrast, the consumption tests we derive here use the full structure of an explicit model, including whether workers have access to liquidity, to derive expressions with modest data requirements. Both of these approaches highlight the need for implicit or explicit assumptions on the structure of the model, especially workers' financial environment, which our behavior test largely avoids. 


\subsection{Workers with Liquidity}

We start with the case when workers have access to financial markets. In this case, our consumption-response test relates the speed of decline in consumption to the elasticity of unemployment duration with respect to unemployment benefits:

Proposition 5 Assume workers have access to financial markets. If unemployment benefits are chosen optimally, the expected absolute decline in consumption during an unemployment spell is

$$
\frac{1}{\gamma} \frac{\alpha_{T}+D}{\alpha_{T}} \frac{\varepsilon_{D, b}}{1+\varepsilon_{D, b}} .
$$

Alternatively, the expected percentage decline in consumption during an unemployment spell should be

$$
\frac{1}{\sigma} \frac{\alpha_{T}+D}{\alpha_{T}} \frac{\varepsilon_{D, b}}{1+\varepsilon_{D, b}}
$$

where $\sigma$ is the coefficient of relative risk aversion evaluated at the consumption level at the start of the unemployment spell, $\sigma=\gamma c_{u}\left(a_{0}\right)$.

The proof is mostly algebraic. First, take the partial derivative with respect to $b$ of both sides of equation (4), holding fixed the tax rate $\tau$ :

$$
\gamma\left(\bar{w}_{b}-1\right)=-\bar{w}_{b} \alpha_{T} \lambda \int_{\bar{w}}^{\infty} u^{\prime}\left(r \alpha_{T}(w-\bar{w})\right) d F(w) .
$$

Since $u^{\prime}(c)=-\gamma u(c)$, we can eliminate the integral using equation (4). Solving this expression for $B=b+\tau$ gives

$$
B=\bar{w}+\frac{1}{r \alpha_{T} \gamma}\left(\frac{1}{\bar{w}_{b}}-\frac{\alpha_{T}+D}{D}\right) .
$$

Second, note that while a worker is unemployed, assets fall at rate $\dot{a}=r a+b-c_{u}(a)=B-\bar{w}$, where the second equality uses equation (2). Since a unit decrease in assets reduces $c_{u}(a)$ by $r$, consumption falls linearly during an unemployment spell, $\dot{c}_{u}=r(B-\bar{w})$. Substitute $B$ from the previous equation.

$$
\dot{c}_{u}=\frac{1}{\alpha_{T} \gamma}\left(\frac{1}{\bar{w}_{b}}-\frac{\alpha_{T}+D}{D}\right)
$$

This holds for any tax and benefit policy. At the optimal policy, we can eliminate $\bar{w}_{b}$ using equation (10) to get

$$
D \dot{c}_{u}=-\frac{1}{\gamma} \frac{\alpha_{T}+D}{\alpha_{T}} \frac{\varepsilon_{D, b}}{1+\varepsilon_{D, b}} .
$$


Finally, if an unemployment spell lasts for $t$ periods, the drop in consumption is $\dot{c}_{u} t$. The density of the duration of an unemployment spell is $e^{-t / D} / D$, so the expected drop in consumption during an unemployment spell is

$$
\int_{0}^{\infty} \frac{e^{-t / D} \dot{c}_{u} t}{D} d t=D \dot{c}_{u}
$$

Combining these equations gives the condition in Proposition 5.

As in most consumption-response tests, this optimality condition relates the average decline in consumption to the elasticity of duration with respect to benefits, but there are some important differences: (i) we use the partial elasticity of unemployment duration with respect to benefits holding taxes fixed, $\varepsilon_{D, b}$, whereas previous studies have considered the effect of a balanced budget increase in benefits and taxes; (ii) the expression describes the average decline in consumption during an unemployment spell; and (iii) the elasticity expression is somewhat different than in previous work.

These points need clarification. First we use the partial elasticity holding taxes fixed because we believe this corresponds to the empirical evidence on the responsiveness of unemployment duration to unemployment benefits. For example, in response to policy experiments, workers who receive higher unemployment benefits are typically not expected to pay higher subsequent taxes. Similarly, in cross-sectional data, workers who receive higher unemployment benefits do not typically pay proportionately higher taxes. In contrast, existing studies measure the elasticity of unemployment duration with respect to benefits as

$$
\frac{b\left(D_{b}(b, \tau)+D_{\tau}(b, \tau) \tau^{\prime}(b)\right)}{D(b, \tau)}
$$

where $\tau^{\prime}(b)$ is the change in taxes required to keep the budget balanced. Of course, our analysis fully incorporates the balanced-budget requirement. It is simply a question of how the elasticity is defined.

Turning now to point (ii), Baily's (1978) original analysis and Gruber's (1997) subsequent work is based on a static analysis. These papers focus on the discrete drop in consumption between employment and unemployment. For example, in his empirical implementation of Baily's (1978) test, Gruber (1997) uses PSID data to look at the drop in food consumption for a worker who is employed in year $t$ and unemployed in year $t+1$. In his dynamic analysis, Chetty (2005) develops a version of Baily's test that suggests looking at the difference in the average marginal utility between employment and unemployment over the worker's entire 
lifetime. Indeed, a similar condition can be derived for our model. Unfortunately, measuring the required difference in marginal utilities is empirically impractical. That is, in general it does not equal the consumption drop used in Gruber (1997), nor the average consumption drop during unemployment required by our test.

Point (iii) is now easily explained. In these papers the optimality condition equates some measure from consumption data to the elasticity of duration. Instead, we find an expression involving the elasticity, but not equal to it. As explained above, the consumption measures differ, so it should not be surprising that the optimality conditions call for equating these to different expressions involving the elasticity.

To implement this test, we plug the usual values $r=0.001, T=165, D=10$, and $\varepsilon_{D, b}=$ 0.88 into equation (16). In addition, assume that the coefficient of relative risk aversion at the start of the unemployment spell is $\sigma=2$. Then the model predicts that consumption should decline by 25 percent during an unemployment spell if the unemployment benefit level is optimal. If instead the observed decline in consumption is smaller, a decrease in unemployment benefits would raise welfare.

We know of no direct evidence on the magnitude of the decline in consumption during an unemployment spell, but there is some indirect evidence based on food consumption and expenditure. Gruber (1997) reports that food expenditures fall by about 6.8 percent when a worker is employed one year and unemployed the next. Aguiar and Hurst (2005) find that the unemployed spend 19 percent less on food than do the employed using cross-sectional data; however, because of an increase in time spent on shopping and food preparation, this translates into only a 5 percent drop in food consumption. Of course, since the income elasticity of food consumption is less than 1, it seems likely that the expenditure on and consumption of other goods declines more than this during an unemployment spell. In addition, even if food consumption could proxy for total consumption, these measures do not generally represent the average decline during a spell. We conclude that, after viewing the available evidence through the lens of our consumption-response test, we are unsure whether current benefits are much too high, much too low, or just right, even if we are sure workers have access to liquidity.

\subsection{Hand-to-Mouth Workers}

We now turn to hand-to-mouth workers. In this case, our test relates the difference in consumption between a worker at the reservation wage, $\bar{w}^{\text {aut }}-\tau$, and an unemployed worker, 
$b$, to the elasticity of unemployment duration:

Proposition 6 Assume workers must consume their income in each period. If unemployment benefits are chosen optimally, the difference between the consumption of an employed worker at the reservation wage and the consumption of an unemployed worker is

$$
\frac{1}{\gamma} \log \left(1+\varepsilon_{D, b}\right)
$$

Equivalently, the percentage drop in consumption when a worker loses a job paying her reservation wage should be

$$
\frac{1}{\sigma} \log \left(1+\varepsilon_{D, b}\right)
$$

where $\sigma$ is the coefficient of relative risk aversion evaluated at the consumption level of a worker earning the reservation wage, $\bar{w}^{\text {aut }}-\tau$.

Again, the proof is algebraic. Totally differentiate equation (6):

$$
\begin{aligned}
\left(u^{\prime}\left(\bar{w}^{\text {aut }}-\tau\right)+\alpha_{T} \lambda \int_{\bar{w}^{\text {aut }}}^{\infty} u^{\prime}\left(\bar{w}^{\text {aut }}-\tau\right) d F(w)\right) & \left(\bar{w}_{b}^{\text {aut }}+\bar{w}_{\tau}^{\text {aut }} \tau^{\prime}(b)-\tau^{\prime}(b)\right) \\
& =u^{\prime}(b)-\alpha_{T} \lambda \int_{\bar{w}^{\text {aut }}}^{\infty} u^{\prime}(w-\tau) d F(w) \tau^{\prime}(b) .
\end{aligned}
$$

The left-hand-side is zero if benefits are chosen optimally, to maximize $\bar{w}^{\text {aut }}(b, \tau(b))-\tau(b)$. Then use equation (9) to eliminate $\tau^{\prime}(b)$ from the right-hand-side:

$$
\frac{u^{\prime}(b)}{\mathbb{E}\left(u^{\prime}(w-\tau) \mid w \geq \bar{w}^{\text {aut }}\right)}=\frac{\alpha_{T}\left(1+\varepsilon_{D, b}\right)}{\alpha_{T}-D \varepsilon_{D, b}},
$$

where the denominator on the left-hand-side is the expectation of the marginal utility of consumption conditional on the wage drawn from $F$ exceeding $\bar{w}^{\text {aut }}$.

Under CARA utility, this simplifies further since the ratio of marginal utility is the same as the ratio of utility,

$$
\frac{u(b)}{\mathbb{E}\left(u(w-\tau) \mid w \geq \bar{w}^{\text {aut }}\right)}=\frac{\alpha_{T}\left(1+\varepsilon_{D, b}\right)}{\alpha_{T}-D \varepsilon_{D, b}} .
$$

Since equation (6) implies

$$
\frac{u(b)}{\mathbb{E}\left(u(w-\tau) \mid w \geq \bar{w}^{\text {aut }}\right)}=\frac{\alpha_{T}}{\left(D+\alpha_{T}\right) \frac{u\left(\bar{w}^{\text {aut }}-\tau\right)}{u(b)}-D},
$$


the previous two equations give

$$
\frac{u(b)}{u\left(\bar{w}^{\text {aut }}-\tau\right)}=1+\varepsilon_{D, b} .
$$

Since $u(c)=-e^{-\gamma c}$, Proposition 6 follows immediately.

Once again, there are three important differences between our condition and most existing formulas based on the response of consumption to unemployment: (i) we use the partial elasticity $\varepsilon_{D, b}$; (ii) we use the difference between the lowest acceptable level of consumption while employed and consumption while unemployed, rather than the average difference; and (iii) the final expression is slightly different than in previous work, with $\log (1+\varepsilon)$ rather than $\varepsilon$.

Given the usual values of $\varepsilon_{D, b}=0.88$ and $\sigma=2$, the critical question in the hand-tomouth model is whether the consumption of a worker employed at her reservation wage is 32 percent more than the consumption of unemployed workers. To measure this, we need to know both the drop in consumption following unemployment and the worker's reservation wage. Data on food expenditures and consumption from Gruber (1997) and Aguiar and Hurst (2005) suggest that many workers may be willing to take jobs which raise their consumption by less than 32 percent, which suggests that workers are currently over-insured. However, this conclusion depends strongly on the hand-to-mouth hypothesis; Proposition 1 shows that if a worker with liquidity takes a job at her reservation wage, her consumption is unchanged.

In our view, there are three drawbacks to the consumption-response tests we have presented here. The first is that the moments of the consumption data that we should look at depend on the structure of financial markets. The second drawback is the unavailability of reliable, high frequency consumption data for goods other than food. In contrast, the behavioral test requires data on the responsiveness of reservation wages to unemployment benefits. This can either be measured using self-reported reservation wages or inferred from the observed pattern of accepted wages. Finally, the behavioral test is robust to assumptions like the predictability of job loss and the extent of heterogeneity. Introducing these modifications is likely to further change the consumption-response tests. 


\section{Conclusions}

This paper argues that the after-tax reservation wage measures the well-being of unemployed workers. Any policy that raises the average after-tax reservation wage is therefore beneficial, and the benefit can be measured by the average increase in the after-tax reservation wage. While we have applied this mainly to thinking about optimal unemployment insurance, the insight is more general. For example, Proposition 3 shows that the after-tax reservation wage encodes the value of liquidity. Going beyond this paper, when evaluating any policy towards the unemployed - examples include severance payments, reemployment bonuses, training subsidies, and job search centers - the key question is whether the policy raises the after-tax reservation wage.

We have assumed CARA preferences throughout the body of this paper. This assumption is convenient but probably not essential. Proposition 2 shows that the after-tax reservation wage measures a hand-to-mouth worker's welfare regardless of her preferences. Moreover, in our companion paper Shimer and Werning (2005), we argue that the behavior of a worker with constant relative risk aversion (CRRA) preferences is quantitatively similar to that of a worker with CARA preferences and the same coefficient of risk aversion if both workers have access to liquidity. Indeed, our intuition for the proof of Proposition 1 explains why this is true: the only reason the after-tax reservation wage would not measure the welfare of an unemployed worker is if workers are willing to take jobs temporarily but not permanently. While this is a theoretical possibility, we doubt that the phenomenon is quantitatively important.

Finally, our paper implies that a key empirical issue is the responsiveness of the reservation wage to unemployment benefits or other labor market policies. Some existing estimates suggest that reservation wages are very responsive, implying huge gains from increasing unemployment benefit levels. Other estimates are much smaller and imply current benefit

levels are too high. An important goal for future empirical research should be to obtain more precise estimates of how labor market policies affect reservation wages. 


\section{Appendix}

\section{A Proof of Proposition 1}

A Convenient CARA Property. We start by proving that

$$
V_{u}(a)=\frac{1}{r} u\left(c_{u}(a)\right) \quad \text { and } \quad V(a, t, w)=\frac{1}{r} u(c(a, t, w))
$$

where $V(a, t, w)$ is the value of an employed worker with assets $a, t$ periods remaining on the job, and a wage $w$. We prove this for the general case where $r$ and $\rho$ are not necessarily equal. With additively separable utility, we have an Euler equation

$$
u^{\prime}\left(c_{s}\right)=e^{(r-\rho)\left(s^{\prime}-s\right)} \mathbb{E}_{s} u^{\prime}\left(c_{s^{\prime}}\right) \quad \forall s^{\prime}>s
$$

where the expectation is taken using all the information available when $c_{s}$ is chosen. With CARA, $u^{\prime}(c)=-\gamma u(c)$, so the Euler equation implies implies per-period utility is a random walk with drift:

$$
u\left(c_{s}\right)=e^{(r-\rho)\left(s^{\prime}-s\right)} \mathbb{E}_{s} u\left(c_{s^{\prime}}\right) .
$$

Now consider the lifetime utility $V_{s}$ at time $s$ of a worker facing some stochastic future consumption path at all future dates $s^{\prime}$ :

$$
V_{s}=\int_{s}^{\infty} e^{-\rho\left(s^{\prime}-s\right)} \mathbb{E}_{s} u\left(c_{s^{\prime}}\right) d s^{\prime}=\int_{s}^{\infty} e^{-\rho\left(s^{\prime}-s\right)} e^{-(r-\rho)\left(s^{\prime}-s\right)} u\left(c_{s}\right) d s^{\prime}=\frac{1}{r} u\left(c_{s}\right) .
$$

The second equation uses equation (19) while the third equation solves the integral.

Shape of the Consumption and Value Functions. The shapes of the consumption and value functions follow immediately from equation (18). It is feasible for a worker with assets $a^{\prime}$ to consume $r a^{\prime}$ more than a worker with assets 0 and vice-versa, assuming the two have the same employment duration and wage. This implies

$$
c(a, t, w)=r a+c(0, t, w)
$$

Next, consider two employed workers, one at a wage $w$ and another at a wage $w^{\prime}$. If each has $t$ periods remaining in his job, the present value (as of the end of the previous period) 
of the difference in earnings is

$$
\left(w-w^{\prime}\right) \int_{0}^{t} e^{-r s} d s \equiv \alpha_{t}\left(w-w^{\prime}\right)
$$

If the present value difference happens to equal the difference in the two workers' asset levels, they have the same resources and will behave the same:

$$
c(a, t, w)=c\left(a+\alpha_{t}\left(w-w^{\prime}\right), t, w^{\prime}\right) .
$$

Combining with equation (20) gives

$$
c(a, t, w)=r\left(a+\alpha_{t}\left(w-w^{\prime}\right)\right)+c\left(0, t, w^{\prime}\right)
$$

for any $w^{\prime}$.

Note that if the job is finished, $t=0$ and $\alpha_{0}=0$, the worker is unemployed so $c(a, 0, w)=$ $c\left(a, 0, w^{\prime}\right)$ for all $w$ and $w^{\prime}$. It is convenient to define $c_{u}(a) \equiv c(a, 0, w)$ as the consumption of a worker who starts a period unemployed and $V_{u}(a) \equiv V(a, 0, w)$ be her value function.

Reservation Wage. Consider a worker who accepts a job at wage $w$. Her value function is $V(a, T, w)$ and so she takes the job if $V(a, T, w) \geq V_{u}(a)$. Using equation (18), this is equivalent to $c(a, T, w) \geq c_{u}(a)$, which by equation (20) implies a reservation wage rule, independent of assets, satisfying

$$
c(0, T, \bar{w})=c_{u}(0)
$$

Combine equation (22) with equation (21), evaluated at $w^{\prime}=\bar{w}$, to get a convenient expression for the consumption of a newly employed worker:

$$
c(a, T, w)=r\left(a+\alpha_{T}(w-\bar{w})\right)+c_{u}(0) .
$$

Behavior of the Employed. A worker who starts a period with $t \geq 0$ periods remaining in her job faces no uncertainty until the job ends and therefore keeps consumption constant. That is, for any $t>0$,

$$
\frac{d c(a(t), t, w)}{d t}=0
$$

where $\dot{a}(t)=r a+w-\tau-c(a(t), t, w)$ is the rate of increase in assets. Differentiating gives

$$
c_{a}(a, t, w)(r a+w-\tau-c(a, t, w))=c_{t}(a, t, w),
$$


where subscripts denote partial derivatives. Note from equation $(21)$ that $c_{a}(a, t, w)=r$, so this is a differential equation for $c$ as a function of $t$ with terminal condition equation (23). The solution is

$$
c(a, t, w)=r a-(w-\tau)\left(e^{r(T-t)}-1\right)+e^{r(T-t)}\left(r \alpha_{T}(w-\bar{w})+c_{u}(0)\right)
$$

This provides an alternate expression for $c(a, 0, w)$, which we know is equal $r a+c_{u}(0)$. Simplifying this equality pins down the constant in the consumption function,

$$
c_{u}(0)=\bar{w}-\tau
$$

Substituting equation (25) into equation (23) yields the consumption functions for unemployed and employed workers found in equation (2) and equation (3), while substituting these into equation (18) gives the value of an unemployed worker in equation (1). All that remains is to determine the worker's reservation wage.

Behavior of the Unemployed. Expected marginal utility for an unemployed worker is a Martingale. This implies

$$
u^{\prime \prime}\left(c_{u}(a)\right) c_{u}^{\prime}(a) \dot{a}+\lambda \int_{\bar{w}}^{\infty}\left(u^{\prime}(c(a, T, w))-u^{\prime}\left(c_{u}(a)\right)\right) d F(w)=0
$$

where $\dot{a}=r a+b-c_{u}(a)=B-\bar{w}$ using equation (25). Since $u^{\prime \prime}(c)=-\gamma u^{\prime}(c)=\gamma^{2} u(c)$ and $c_{u}^{\prime}(a)=r$, we can rewrite this as

$$
\gamma r u\left(c_{u}(a)\right)(B-\bar{w})=\lambda \int_{\bar{w}}^{\infty}\left(u(c(a, T, w))-u\left(c_{u}(a)\right)\right) d F(w) .
$$

Next, use $u\left(c_{1}\right) / u\left(c_{2}\right)=-u\left(c_{1}-c_{2}\right)$ and $u(0)=-1$ to get

$$
\left.\gamma r(\bar{w}-B)=\lambda \int_{\bar{w}}^{\infty}\left(u\left(c(a, T, w)-c_{u}(a)\right)\right)+1\right) d F(w)
$$

Simplify using equation (23) yields equation (4). This completes the characterization of worker behavior in Proposition 1. 


\section{B Proof of Proposition 3}

We start with two inequalities. At any $w \geq \tilde{w}$,

$$
\begin{gathered}
-u(B-\tilde{w})-1=\exp (\gamma(\tilde{w}-B))-1>\gamma(\tilde{w}-B) \\
1+u\left(r \alpha_{T}(w-\tilde{w})\right) \geq r \alpha_{T}(1+u(w-\tilde{w})) .
\end{gathered}
$$

The first equality uses the definition of $u$ and the first inequality uses convexity of the exponential function. To prove the second inequality, note that $1-y \geq e^{-x y}-y e^{-x}$ when $x>0$ and $y \in[0,1]$. When $x=0$, this is trivially true. Moreover, the derivative of the right-hand-side with respect to $x$ is $y\left(e^{-x}-e^{-x y}\right)$. Since $y \in[0,1]$ and $x \geq 0, x \geq x y$ and hence $e^{-x} \leq e^{-x y}$, so the right-hand-side is decreasing in $x$. Hence the inequality holds for any positive $x$. If $x=\gamma(w-\tilde{w})>0$ and $y=r \alpha_{T} \in[0,1]$, this is equivalent to the desired inequality.

Now suppose $\bar{w}$ solves equation (4). The previous inequalities imply

$$
\begin{aligned}
-u(B-\bar{w})-1> & \gamma(\bar{w}-B)= \\
& \frac{\lambda}{r} \int_{\bar{w}}^{\infty}\left(1+u\left(r \alpha_{T}(w-\bar{w})\right)\right) d F(w) \geq \alpha_{T} \lambda \int_{\bar{w}}^{\infty}(1+u(w-\bar{w})) d F(w) .
\end{aligned}
$$

It is easy to confirm that the first expression is decreasing in $\bar{w}$ and the last expression is increasing, so the solution to

$$
-u\left(B-\bar{w}^{\text {aut }}\right)-1=\alpha_{T} \lambda \int_{\bar{w}^{\text {aut }}}^{\infty}\left(1+u\left(w-\bar{w}^{\text {aut }}\right)\right) d F(w)
$$

requires $\bar{w}^{\text {aut }}<\bar{w}$. Under CARA utility, $u\left(c_{1}+c_{2}\right)=-u\left(c_{1}\right) u\left(c_{2}\right)$, so this is equivalent to the reservation wage equation (6).

Finally, under financial autarky, equation (5) shows that an unemployed worker's utility is $u\left(\bar{w}^{\text {aut }}-\tau\right) / \rho$. With access to financial markets, equation $(1)$ shows that it is $u(r a+\bar{w}-\tau) / \rho$. The worker is indifferent to the scenarios if $a=\left(\bar{w}^{\text {aut }}-\bar{w}\right) / r$, a reduction in assets that lowers the worker's consumption by $r a=\bar{w}^{\text {aut }}-\bar{w}$ in every future period. 


\section{References}

Acemoglu, Daron and Robert Shimer, "Efficient Unemployment Insurance," Journal of Political Economy, 1999, 107 (5), 893-928.

_ and _ , "Productivity gains from unemployment insurance," European Economic Review, 2000, 44 (7), 1195-1224.

Aguiar, Mark and Erik Hurst, "Consumption versus Expenditure," Journal of Political Economy, 2005, 113 (5), 919-948.

Alvarez, Fernando and Marcelo Veracierto, "Severance payments in an economy with frictions," Journal of Monetary Economics, 2001, 47 (3), 477-498.

Baily, Martin Neil, "Some Aspects of Optimal Unemployment Insurance," Journal of Public Economics, 1978, 10 (3), 379-402.

Bloemen, Hans G. and Elena G. F. Stancanelli, "Individual Wealth, Reservation Wages, and Transitions into Employment," Journal of Labor Economics, 2001, 19 (2), 400-439.

Chetty, Raj, "A General Formula for the Optimal Level of Social Insurance," 2005. Manuscript, UC-Berkeley, September.

Ehrenberg, Ronald G and Ronald L Oaxaca, "Unemployment Insurance, Duration of Unemployment, and Subsequent Wage Gain," American Economic Review, 1976, 66 (5), 754-66.

Feldstein, Martin, "Rethinking Social Insurance," American Economic Review, March 2005, 95 (1), 1-24.

- and James Poterba, "Unemployment Insurance and Reservation Wages," Journal of Public Economics, February-March 1984, 23 (1-2), 141-167.

Fishe, Raymond P. H., "Unemployment Insurance and the Reservation Wage of the Unemployed," The Review of Economics and Statistics, 1982, 64 (1), 12-17.

Gruber, Jonathan, "The Consumption Smoothing Benefits of Unemployment Insurance," American Economic Review, March 1997, 87 (1), 192-205.

Hansen, Gary D and Ayse Imrohoroglu, "The Role of Unemployment Insurance in an Economy with Liquidity Constraints and Moral Hazard," Journal of Political Economy, $1992,100(1), 118-42$.

Hopenhayn, Hugo and Juan Pablo Nicolini, "Optimal Unemployment Insurance," Journal of Political Economy, 1997, 105 (2), 412-438. 
Krueger, Alan and Bruce Meyer, "Labor Supply Effects of Social Insurance," in Alan Auerbach and Martin Feldstein, eds., Handbook of Public Economics, Elsevier Science B.V., 2002, chapter 33, pp. 2327-2392.

McCall, John, "Economics of Information and Job Search," Quarterly Journal of Economics, 1970, 84 (1), 113-126.

Meyer, Bruce, "Unemployment Insurance and Unemployment Spells," Econometrica, July 1990, 58 (4), 757-782.

Shavell, Steven and Laurence Weiss, "Optimal Payment of Unemployment-Insurance Benefits over Time," Journal of Political Economy, 1979, 87 (6), 1347-1362.

Shimer, Robert and Iván Werning, "Liquidity and Insurance for the Unemployed," Staff Report 366, Federal Reserve Bank of Minneapolis December 2005. 